\title{
EFFECT OF TOPICAL CYCLOSPORINE (0.05\%) ON CONJUNCTIVAL IMPRESSION CYTOLOGY IN DRY EYE.
}

Ruchika Agarwal' ${ }^{1}$ A.M Jain², NutanSaxena ${ }^{3}$, AnitaThakur4.
1. Assistant Professor, Department of Ophthalmology, Rama Medical College, Kanpur.
2. Professor, Department of Ophthalmology, Rama Medical College, Kanpur.
3. Assistant Professor, Department of Ophthalmology, Rama Medical College, Kanpur.
4. Associate Professor, Department of Ophthalmology, Rama Medical College, Kanpur.

\section{CORRESPONDING AUTHOR}

Dr Ruchika Agarwal,

7/57/9, Ratan Enclave,

Tilak Nagar, Kanpur.

Email- ruchidrjain@yahoo.co.in

\section{HOW TO CITE THIS ARTICLE:}

Ruchika Agarwal, A.M Jain, Nutan Saxena, Anita Thakur. "Effect of Topical Cyclosporine (0.05\%) on Conjunctival Impression Cytology in Dry Eye". Journal of Evolution of Medical and Dental Sciences 2013; Vol2, Issue 24, June 17; Page: 4277-4281.

ABSTRACT: AIM: To study the effect of topical cyclosporine(0.05\%) on conjunctival impression cytology in dry eye MATERIAL AND METHODS: Thirty patients of dry eye (schirmer's $<10$ ) were given topical cyclosporin(0.05\%)twice daily and HPMC for a period of three months .Thirty patients were given HPMC alone and they acted as controls. Conjunctival impression cytology was taken at an interval of two weeks till three months. RESULTS: Conjunctival impression cytology number of cases showing goblet cell deficiency reduced from 23 to 16 and those showing squamous metaplasia reduced from 22 to 17 showing a marginally significant improvement in both the parameters $(p=0.057)$.Controls did not showed significant improvement in any of the tests. CONCLUSION: Topical CsA $0.05 \%$ twice daily was found effective in dry eye disorder as it led to statistically significant improvement in conjunctival impression cytology.

KEYWORDS: Cyclosporine, conjunctival impression cytology

INTRODUCTION: Recent population based surveys indicates that dry eye disease affects millions of people worldwide.Its prevalence is $11 \%-17 \%$ in the general population and $29 \%$ in clinical optometry practices ${ }^{1}$.Despite affecting millions and substantially altering the productivity and quality of life, treatment modalities for dry eye disease have been palliative, at best consisting of lubricating eye drops or punctal occlusion procedures, which focus either on tear replacement or tear preservation and provide only temporary and incomplete symptomatic relief.

With this emerging new concept, interesting advances in the treatment of dry eye diseases are being introduced to control the underlying pathogenesis of the disease. One such modality of treatment is the use of topical cyclosporine - A (CsA). Topical CsA inhibits dry eye inflammatory cascade which involves activation of immune response, release of inflammatory mediators and apoptosis. It limits $\mathrm{T}$ - lymphocyte activation by inhibiting the expression of HLA-DR and other signals that activate $\mathrm{T}$ - lymphocytes thus, exerting a local immunomodulatory effect. Thus, the inflammation is decreased and ocular surface and lacrimal glands recover prompting towards 
normal tear production. The topical CsA administration not only alleviates signs and symptoms of the disease but also controls the underlying causative inflammatory processes.

The present study was undertaken to investigate the effect of topical CsA $(0.05 \%)$ ophthalmic emulsion on conjunctival impression cytology in dry eye.

MATERIAL AND METHODS: A Prospective interventional case study was undertaken. The study included patients attending the OPD of Ram Lal Eye Hospital wing of Government Medical College, Amritsar. Sixty cases of dry eye were selected from the Outpatient Department. Inclusion criteria were a reading of less than $10 \mathrm{~mm}$ wetting of Whattman 41 filter paper strips after topical instillation of 4\% xylocaine (schirmer's two tests) was considered significant for the diagnosis of Dry eye. Exclusion criteria included any external ocular disease including active ocular infection, Contact lens wearers, previous history of herpetic keratitis, Degenerative corneal diseases, Pregnant and lactating females and those on systemic drugs like Beta-blockers, Anticholinergics, and Halothane etc. All medications both systemic and local (except topical HPMC 0.3\%) were stopped for two weeks before taking the baseline readings.

Two groups comprising of 30 cases each were enrolled for the present study. Group A included those 30 cases which were subjected to $0.05 \%$ Cyclosporine (b.d) and $0.3 \%$ Hydroxypropylmethylcellulose (q.i.d). Group B included those 30cases, which were subjected to 0.3\% Hydroxypropylmethylcellulose (q.i.d) alone.

An informed consent was obtained from each case at the initial visit followed by a detailed history, examination and investigations. Observations were noted in a standard proforma. Follow up was done at an interval of two weeks till twelve weeks. Conjunctival impression cytology was carried out after anaesthetizing the eye with 4\% topical xylocaine. Round sheets of cellulose acetate paper (Millipore; Type HA, pore size 0.45), $25 \mathrm{~mm}$ in diameter, were cut into triangular pieces by dividing the circumference into arcs of $5 \mathrm{~mm}$ and cutting radially to the centre. The pointed tip facilitates holding and transferring of the paper. The upper lid was gently retracted. Using a forceps, a strip of the filter paper was placed in the superotemporal area of the bulbar conjunctiva $2-4 \mathrm{~mm}$ away from the limbus. The paper was gently pressed with a glass rod and left in place for 3-5 seconds and then was lifted using a plain forceps and was then transferred to a rubber stopped glass vial containing the fixative solution and labeled. The composition of the fixative solution is as follows (ICEPO 1988) 75ml ethyl alcohol (95\%),25ml distilled water ,5ml Glacial acetic acid,5ml Formaldehyde (37\%) .The specimens were ready for staining after 20 minutes or can remain in the fixative for several weeks before staining. Periodic Acid Schiff (PAS) Reagent stains mucus spots and goblet cells as bright pink .Sodium metabisulphite fixes the PAS stain. Harris Haematoxylin counterstains the epithelial nuclei as bluish purple. Ethanol baths are used for drying the samples. Finally, the specimens were transferred on to a glass slide, mounted, a cover slip put and then examined under the microscope. The following structures were looked under the microscope Epithelial cells, Goblet cells, Mucin spots, Mucin strands, Foreign body debris Other cells like polymorphonuclear leucocytes. Normal epithelial cells look like sheets of small cells or some individual cells whose nucleus fills most of the cytoplasm whereas abnormal cells are enlarged, separated with a nucleus of the same size, shrunken or absent. Goblet cells are seen as smooth, PAS positive, pink plump structures containing mucin. Normally, the goblet cell density is greater in the nasal palpebral conjunctiva, decreasing in density in the order of temporal palpebral to bulbar 
conjunctiva near the limbus. Each of the specimens was analysed for goblet cells and changes suggestive of squamous metaplasia. The transformation of normal columnar epithelium into stratified squamous epithelium was looked for in each slide before and after treatment in each group.

RESULTS: As stated previously conjunctival cytology was taken at the start of the treatment and then at the end of treatment. In Group A, goblet cell deficiency was found in 23 cases initially while 7 cases had normal number of cells. Post treatment that is after a period of three months the no of cases having normal goblet cell density increased to 14 while 16 cases continued to have deficient goblet cells. This increase in number of cells was found to be marginally significant ( $\mathrm{p}$ value = 0.056)

\section{TABLE 1: Goblet cell deficiency in GROUP A}

\begin{tabular}{|l|l|l|}
\hline & Pre Treatment & Post Treatment \\
\hline $\begin{array}{l}\text { No of cases showing goblet } \\
\text { cell deficiency }\end{array}$ & 23 & 16 \\
\hline $\begin{array}{l}\text { No of cases showing normal } \\
\text { cytology. }\end{array}$ & 7 & 14 \\
\hline
\end{tabular}

In Group B, goblet cell deficiency was found in 24 cases initially while 6 cases had normal number of cells. Post treatment 21 cases persisted with goblet cell deficiency while 9 cases showed normal density and this increase was not at all significant.

\section{TABLE 2: Goblet cell deficiency in GROUP B}

\begin{tabular}{|l|l|l|}
\hline & Pre Treatment & Post Treatment \\
\hline No of cases showing goblet cell deficiency & 24 & 21 \\
\hline No of cases showing normal cytology. & 6 & 9 \\
\hline
\end{tabular}

In group A 22 cases showed varied amount of squamous metaplasia Most of the cases had moderate degree of squamous metaplasia. After treatment the number reduced to 17 and this change was again marginally significant ( $\mathrm{p}$ value= 0.057 ). In Group B the number of cases showing metaplastic changes was 23 initially and after treatment in this group the number remained almost static. Although there was improvement in three cases it was not statistically significant.

\section{SQUAMOUS METAPLASIA}

TABLE 3. No of cases showing squamous metaplasia

\begin{tabular}{|l|l|l|}
\hline Group & Pre Treatment & Post Treatment \\
\hline A & 22 & 17 \\
\hline B & 23 & 20 \\
\hline
\end{tabular}

DISCUSSION: Initially 8 cases in Group A had normal cytology while 22 cases showed evidence of squamous metaplasia as is known to be associated with dry eye. Goblet cell deficiency was present in 23 cases in this group before treatment. Post treatment 11 cases showed abnormal cytology with squamous metaplasia and goblet cell deficiency persisted in 16 cases. After treatment with topical cyclosporine $(0.05 \%)$ for three months marginally significant improvement $(p=0.056)$ was noted in 
both the above mentioned parameters. Although the improvement in cytology was not highly significant review of previous studies reveal that if follow up is carried for a longer period of time up to six months the results turn out to be significant. No significant change was seen in cytology of Group B cases.

Kunert et also showed a significant decrease in the immune markers HLA-DR and CD 11 after treatment with $0.05 \%$ cyclosporine- $\mathrm{A}^{87}$. They have also found significantly increase in the density of conjunctival goblet cells after 6 months of treatment of cyclosporine-A $0.05 \%{ }^{2}$.Oh HJ, You IC, Yoon KC noticed reduction in the degree of conjunctival squamous cell metaplasia $(\mathrm{P}=0.02)$ and increment in the density of goblet cell $(\mathrm{P}=0.04)$ after 3 month of treatment with topical $0.1 \%$ cyclosporine $\mathrm{A}$ in patients with dry eye associated with thyroid ophthalmopathy ${ }^{3}$.Turner et al showed that conjunctival levels of the inflammatory cytokine IL- 6 significantly decreased after 6 months of treatment of cyclosporine-A $0.05 \% \%^{4}$.

To conclude Topical CsA $0.05 \%$ twice daily was found to be effective in dry eye as it led to statistically significant improvement in conjunctival impression cytology .

\section{BIBLIOGRAPHY}

1. Brewitt H, Sistani F. Dry Eye disease: The scale of Problem. Surv Ophthalmol 2001; 45 (Suppl 2): S199-202.

2. KS Kunert; AS tisdale, Ilene K. Gipson. Goblet cell numbers and epithelial proliferation in the conjunctiva of patients with Dry Eye syndrome treated with cyclosporine. Arch Ophthalmol 2002; 120: 330-337.

3. Oh HJ, You IC, Yoon KC. J Korean Ophtalmol Soc. May 2007; 48(5):630-636.

4. Turner K, Pflugfelder SC, Ji Z, Feuer WJ, Stern M, Reis BL. Interleukin-6 levels in the conjunctival epithelium of patients with dry eye disease treated with cyclosporine ophthalmic emulsion. Cornea 2000 Jul; 19(4):492-6

\section{CONJUNCTIVAL IMPRESSION CYTOLOGY MICROPHOTOGRAPH}




\section{ORIGINAL ARTICLE}

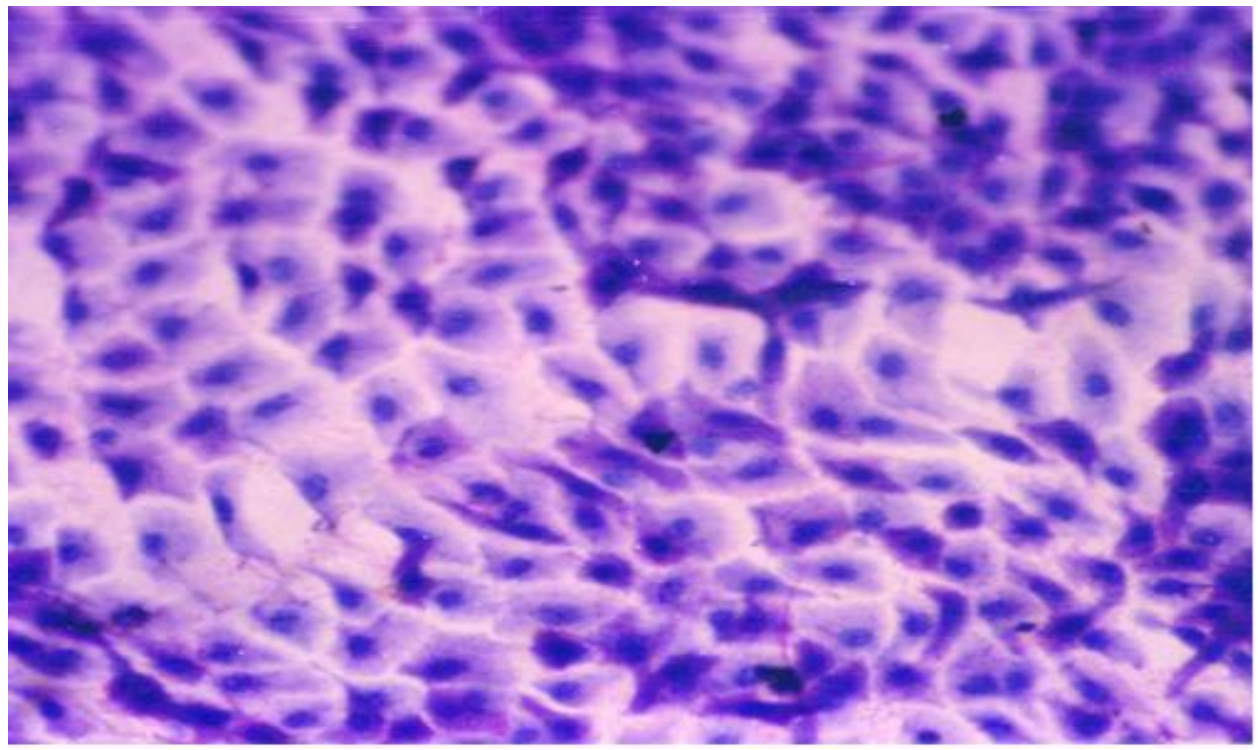

GROUP A: PRE TREATMENT SHOWING ABSENCE OF GOBLET CELLS AND SQUAMOUS METAPLASIA

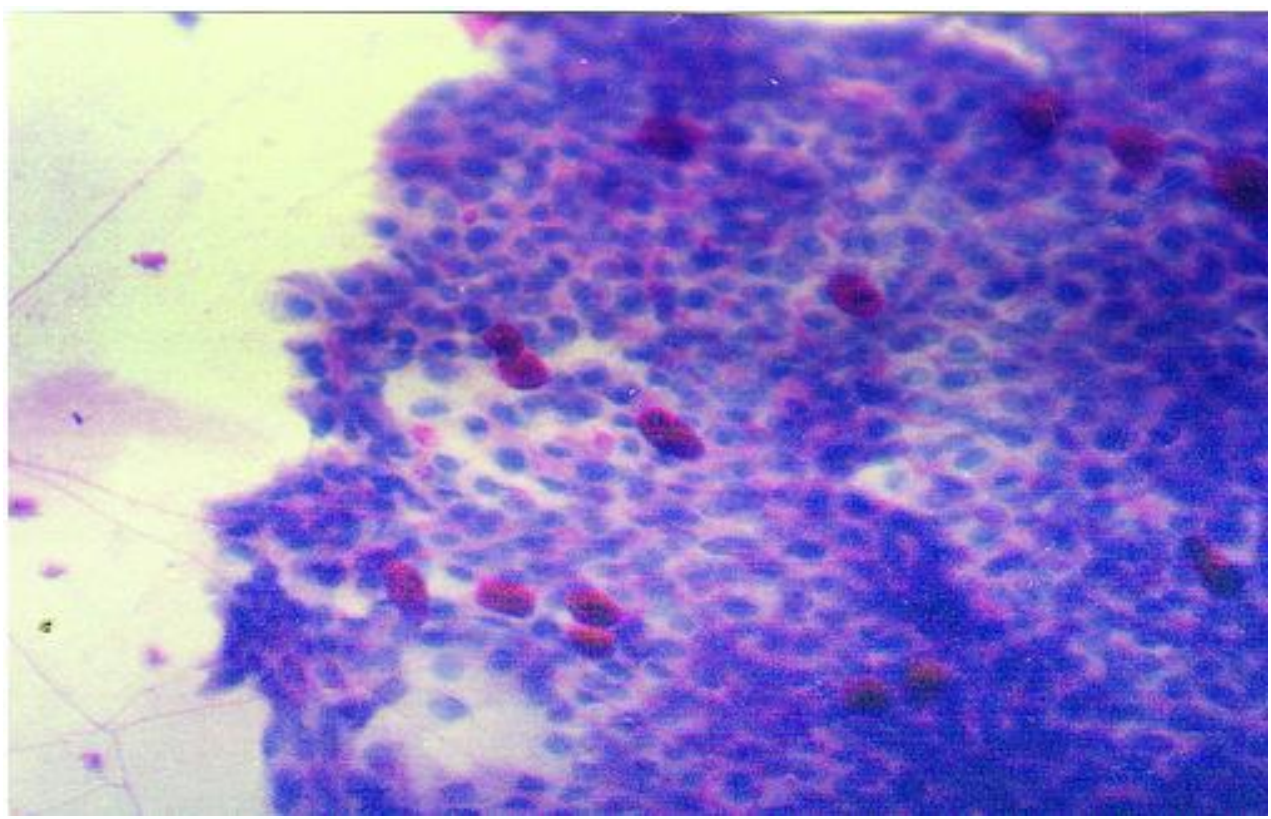

GROUP A: POST TREATMENT SHOWING REVERSAL OF SQUAMOUS METAPLASIA AND ABUNDANT GOBLET 